\title{
Progressive Scoliosis-A Sinister Finding
}

\author{
K. SHREEDHARA AVABRATHA, A.T.K. RAU, RADHA PAI
}

\begin{abstract}
Germ cell tumours are relatively uncommon childhood tumours. Extragonadal germ cell tumours represent approximately two thirds of pediatric germ cell tumours. $\beta$-HCG and serum AFP serve as tumour markers in making the diagnosis. Here we report a 5-year-old boy with pediatric germ cell tumour of the posterior mediastinum which presented as progressive scoliosis without any elevation of tumour marker levels.
\end{abstract}

\section{INTRODUCTION}

Germ cell tumours (GCT) are relatively uncommon, accounting for approximately $3 \%$ of all childhood malignancies. Extragonadal neoplasms in children represent approximately two thirds of pediatric germ cell tumours. ${ }^{1}$ Extra gonadal germ cell tumours are found along the midline (germinal ridge) from cranium to the retroperitoneum to pre-sacral areas. Mediastinal GCTs account for about $15 \%$ of all mediastinal cysts and tumours. ${ }^{2} \beta-\mathrm{HCG}$ and serum AFP serve as tumour markers in making the diagnosis of GCT. Here we report a case of pediatric GCT of the posterior mediastinum, which presented as progressive scoliosis without elevation of any of the tumour markers.

CASE : A 5-year-old boy presented to our hospital with intermittent back pain of 8 months duration \& tilt while walking for the

Department of Pediatric Oncology Unit, Kasturba Medical College

Hospital, Attavar, Mangalore-575 001. Karnataka State.

Correspondence to: DR. (LT. COL) A.T.K. RAU,

E-mail:atkrau@sancharnet.in previous 4 months. There was history of easy fatigability and weight loss.

The child was a product of nonconsanguineous marriage with normal birth history and development. Child was immunized for age. On examination child weighed $14 \mathrm{~kg}$ (expected 18kg) with no significant lymphadenopathy or dysmorphic facies. BP was normal. He had significant scoliosis with convexity towards right $\left(\mathrm{T}_{5}-\mathrm{T}_{8}\right.$ region). Clinically cardiovascular and respiratory systems were normal. There was no organomegaly. Detailed neurological examination did not reveal any motor or sensory abnormality. Gait was normal except for mild tilt of the upper torso to the left.

Hemogram and serum biochemistry were within normal limits except that total counts were high $(24,500 / \mathrm{cmm})$. Lactate dehydrogenase $(\mathrm{LDH})$ was slightly elevated $(294 \mathrm{u} / \mathrm{l}$, Normal : 90 - $180 \mathrm{u} / \mathrm{l})$. Chest X-ray showed scoliosis and a significant retrocardiac shadow. CT scan of thorax showed a posterior mediastinal mass lesion measuring $47.4 \mathrm{~mm} \mathrm{x}$ $34.2 \mathrm{~mm}$ with central necrotic area with evidence of erosion of the $6^{\text {th }}, 7^{\text {th }}$ and $8^{\text {th }}$ rib posteriorly and $6^{\text {th }} \& 7^{\text {th }}$ vertebral body along with the pedicles on the left side and extension of the lesion posteriorly in the extradural space causing compression of the spinal cord on the right side (fig.1). Serum Ferritin, AFP, $\beta$ - HCG, Alkaline Pho6sphatase, urine vanilyl mandelic acid (VMA) \& homovanillic acid (HVA) were 


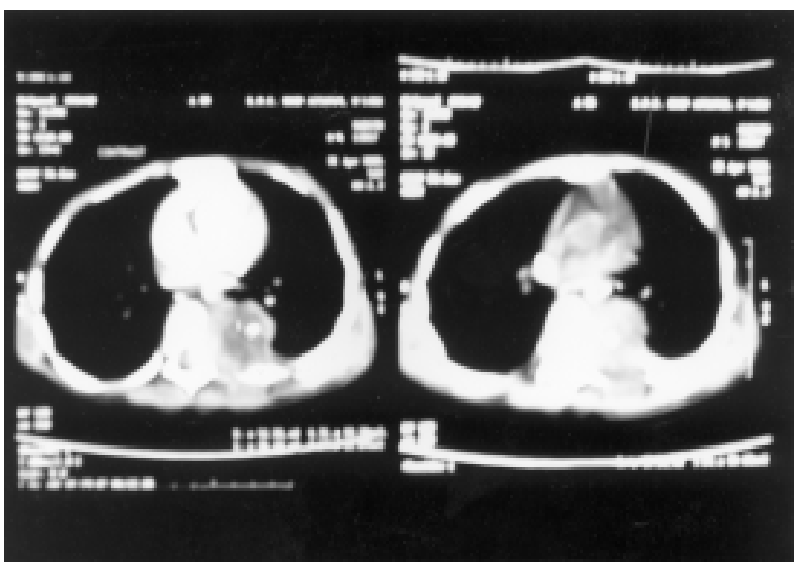

Fig 1. CT scan of thorax showing the posterior mediastinal tumour.

within normal limits. Ultrasonography of abdomen and testes was normal. Bone marrow biopsy and isotope bone scan did not reveal any evidence of bony metastasis.

The child was taken up for excision of the tumour by posterolateral thoractomy. A solid tumour, measuring $6 \times 8 \mathrm{~cm}$ with moderate vascularity was found adherent to and eroding the $6^{\text {th }}, 7^{\text {th }}, \& 8^{\text {th }}$ rib as well as involving the cortex of the adjacent vertebral bodies. A part of the tumour extended into the spinal canal and this was excised along with $6^{\text {th }}, 7^{\text {th }} \& 8^{\text {th }}$ rib posteriorly. Histopathology revealed tumour cells with high nuclear:chromatin ratio and marked pleomorphism favouring the diagnosis of germ cell tumour - Embryonal carcinoma with associated germinoma (fig.2). Immunohistochemistry revealed the tumour cells positive for $\mathrm{AE}_{1} / \mathrm{AE}$ and negative for $\mathrm{AFP}$, $\mathrm{CD}_{30}$, placental alkaline phoshatase (PLAP), creatinine kinase (CK), epithelial membrane antigen (EMA), Vimentin, leucocyte common antigen(LCA), $\mathrm{CD}_{20}$, C-kit. Although not classic, these features were compatible with the diagnosis of germ cell tumour (Embryonal carcinoma).

The child received three cycles of Cisplatin, Etoposide and Bleomycin following which he underwent resection of residual

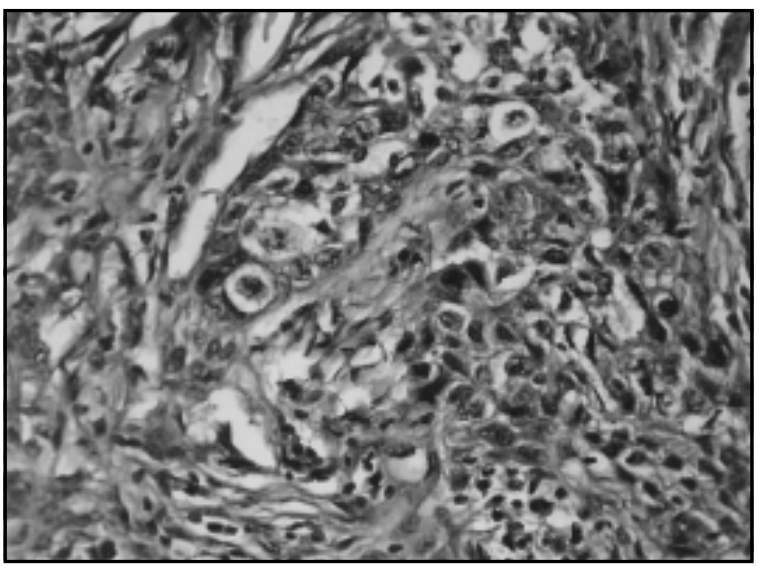

Fig 2. Histopathology showing pleomorphic epithelial cells arranged in glandular and diffuse pattern with vesicular nuclei and prominent nucleoli (H \& E x 400).

tumour and received two more cycles of chemotherapy. He remained well for about 8 weeks but subsequently relapsed in that scoliosis increased and tumour mass was noted again in the primary area. PET scan of the lesion revealed intense activity. However parents were unwilling for further therapy and the child was lost to follow up.

\section{DISCUSSION}

Germ cell tumours are thought to arise from primordial germ cells derived from the yolk sac endoderm. Germ cells migrate along the germinal ridge and arrest any where, where they form extragonadal GCT. The most common site of extragonadal germ cell tumour in children is the sacrococygeal region followed by the anterior mediastinum, pineal gland, retroperitoneum and less commonly the neck, stomach and vagina. ${ }^{1}$ Thoracic germ cell tumours are usually, but not exclusively located in the anterior mediastinum. ${ }^{3}$ In our case, the tumour was in the posterior mediastinum.

Common presentations include-symptoms related to the site of involvement, pain being the common symptom. Our case presented with features of back pain \& scoliosis. Initial hemogram and biochemistry were within normal 
limits except that total counts were high. Serum LDH level was slightly elevated. Elevated LDH levels in extragonadal GCT patients, may reflect rapid, nonspecific tumour cell growth in the setting of advanced, bulky malignancy. In the absence of a hemolytic process an elevated LDH may provide an early diagnostic clue for potentially treatable malignancies including lympho-proliferative and germ cell neoplasms. As VMA, HVA results were normal and CT scan of thorax showed erosion of ribs, the differential diagnosis of round cell tumour (Ewing's or primitive neuroectodermal tumour) was also considered. Histopathology of the lesion however revealed a germ cell tumour.

Primary extragonadal disease can occur in the absence of a neoplasm of the testes. ${ }^{5}$ as seen in this case. Like gonadal neoplasms, extragonadal GCTs are classified as either seminomatous or non seminomatous. The latter is usually characterized by elevated levels of serum tumour markers, the most important being the AFP and $\beta$ - HCG levels. In our patient, both of these were within normal limits. Clinical and histopathologic characteristics are useful in the diagnosis of GCTs when tumour markers are non contributory. Incorrect interpretation of these neoplasms as a poorly differentiated malignancy without a specific diagnosis may deprive the patient of appropriate chemotherapy. ${ }^{6}$
The need for surgical debulking in patients with extra gonadal GCT has been emphasized. ${ }^{4}$ However, with the advent of cisplatin based intensive therapy with marrow rescue has improved the prognosis tremendously over the last decade or so. In spite of this, the overall 5 year disease free survival in nonseminomatous extragonadal GCTs in adolescents and adults in most series is about $30-50 \%$. Children with classical extragonadal GCTs do far better.

\section{REFERENCES:}

1. Rescorla FJ, Pediatric germ cell tumours. Semin Surg Oncol. 1999;16(2):144-158.

2. Weidner N, Germ - cell tumours of the mediastinum. Semin Diagn Pathol. 1999;16(1):42-50.

3. Castleberry RP, Cushing B, Perlman E, Hawkins EP, Germ cell tumours. In : Pizzo PA, Poplack DG editors, Principles and practice of Pediatric Oncology, $3^{\text {rd }}$ ed. Philadelphia Lippincott - Raven; 1997;921-943.

4. Mcleod DG, Taylor HG, Skoog SJ, Knight RD, Dawson NA, Waxman JA, Extragondal germ cell tumours clinico pathologic findings and treatment experience in 12 patients. Cancer 1988;61:1187-1191.

5. Goss PE, Schwertfeger L, Blackstein ME, Iscoe NA, Ginsberg RJ, Simpson WJ, et al. Extragonadal germ cell tumours. A 14 -year Toranto experience. Cancer 1994;73:1971-79.

6. Stanley $M W$, Powers $C N$, Pitman $M B$, Korourian $S$, Bardales RH, Khurana K. Cytology of germ cell tumours: extragonadal, extrcranial masses and intraoperative problems. Cancer 1997;25:81(4):220-7. 